\title{
Breast cancer awareness and breast self-examination among future female university graduates: comparison between medical and non-medical students
}

\author{
Elsadig Yousif Mohamed*, Waqas Sami, Abdullah Atallah Alenezi, \\ Abdulrahman Mubarak Almutairi, Ahmad Khalid Alsalboud, Khalid Mohammad Alhusainy, \\ Mohammad Awadh Almutairi, Syed Meraj Ahmed, Khalid Altohami Medani, \\ Mohammed Abdullah Al Mansour, Mansour Khatir Alzahrani, Talal Shakhs Algamdi, \\ Fahad Bin Mohamed Alfhaid, Tahir Ansari
}

College of Medicine, Majmaah University, Saudi Arabia

Received: 05 January 2016

Revised: 16 February 2016

Accepted: 18 February 2016

\section{*Correspondence:}

Dr. Elsadig Yousif Mohamed,

E-mail: elsadigoo@gmail.com

Copyright: ( ) the author(s), publisher and licensee Medip Academy. This is an open-access article distributed under the terms of the Creative Commons Attribution Non-Commercial License, which permits unrestricted non-commercial use, distribution, and reproduction in any medium, provided the original work is properly cited.

\begin{abstract}
Background: Breast cancer is a common health problem among females in Saudi Arabia. The disease account for $27 \%$ of all female malignancies representing $25.1 \%$ of all newly diagnosed female cancers. The objectives of the current study were to assess the level of carcinoma breast awareness of female university students, Majmaah University in Saudi Arabia and to compare the level of awareness, breast self-examination and breast cancer screening between medical and non-medical students.

Methods: The current study was a cross-sectional, conducted among female students in Majmaah University in Saudi Arabia. The stratified and the systematic sampling were employed to select the colleges and the students respectively. The sample size was calculated as 325 . Data was collected by a pre tested questionnaire and analyzed by SPSS.

Results: The university students who acquired good knowledge were 111 (34.2\%). Students who acquired average and poor knowledge were $42.2 \%$ and $23.6 \%$ respectively. Medical students who had good knowledge were $37.6 \%$ compared to $26.9 \%$ of non-medical students. The results showed that 94 (28.9\%) of the participants practice breast self-examination and $25(7.6 \%)$ performed a screening test.

Conclusions: The study concluded that Majmaah University students' awareness of carcinoma breast is low. There is no significant difference in the level of awareness between students of medical colleges and those of non-medical colleges. The level of practicing breast self-examination and performing screening test for carcinoma breast among female university students is low. There is a significant difference in performing carcinoma breast screening test between medical and non-medical students.
\end{abstract}

Keywords: Breast cancer, Awareness, Breast self-examination, Screening test

\section{INTRODUCTION}

Breast cancer is the most common cancer in women in both developed and developing world. It is estimated that 508,000 women died in 2011 due to breast cancer. ${ }^{1}$ The incidence of breast cancer is increasing in the developing world due to increase life expectancy, increase urbanization and adoption of western lifestyles. Although some risk reduction might be achieved with prevention, these strategies cannot eliminate the majority of breast 
cancers because many patients present at very late stages in many countries. Therefore, early detection in order to improve breast cancer outcome and survival remains the cornerstone of breast cancer control. ${ }^{2}$

Incidence rates of breast cancer vary greatly worldwide from 19.3 per 100,000 women in Eastern Africa to 89.7 per 100,000 women in Western Europe. In most of the developing regions the incidence rates are below 40 per 100,000 women. $^{3}$

Breast cancer survival rates vary greatly worldwide, ranging from $80 \%$ or over in North America, Sweden and Japan to around $60 \%$ in middle-income countries and below $40 \%$ in low-income countries. The low survival rates in less developed countries can be explained mainly by the lack of early detection programs, resulting in a high proportion of women presenting with late-stage disease, as well as by the lack of adequate diagnosis and treatment facilities. ${ }^{4}$

Although the incidence of breast cancer is lower in Asia, the cause-specific mortality in most countries is much higher compared to Western countries. Up to $25 \%$ of all breast cancer patients in Asia are young. Young age, by itself, is a known indicator of poor prognosis among breast cancer patients. ${ }^{5}$

In the Eastern Mediterranean region (EMR), breast cancer is the most commonly diagnosed cancer in women and the second leading cause of cancer-related deaths. ${ }^{6}$

In the gulf region, profound lack of knowledge about breast cancer was noted among female university students in UAE universities and school teachers in Quait. ${ }^{7}$ The most prominent gaps in knowledge identified were those concerning breast cancer screening methods. ${ }^{8}$

In Saudi Arabia, the absence of a national breast cancer control program combined with cultural barriers to screening explain the fact that most of the breast cancer cases present at advanced stage than in developed countries. ${ }^{9,10}$ Breast cancer in Saudi Arabia account for $27 \%$ of all female malignancies in 2010, representing $25.1 \%$ of all newly diagnosed female cancers. ${ }^{11,12}$ Studies of breast cancer awareness among Saudi females in different regions found that Saudi female's level of awareness of breast cancer was very inadequate. ${ }^{13-15}$ Little is known about breast cancer knowledge and awareness among students of Majmaah University, Saudi Arabia. Therefore, the objectives of the current study were to assess the level of awareness of female university students of Majmaah University in Saudi Arabia, to compare the level of awareness between medical and non-medical students, to assess the level of practicing breast self-examination and to determine the rate of breast cancer screening among the study population.

\section{METHODS}

This study was a cross-sectional about breast cancer awareness of female students in Majmaah University in Saudi Arabia. Majmaah city is the capital of Majmaah province in Riyadh region. Majmaah University, which contains thirteen collages for both sexes, was established in 2009 to serve the population in Sudair area in the centre of the kingdom.

The study population was the undergraduate female students at the Colleges of Majmaah University which included the applied medical science college, college of medicine, education college as well as the computer sciences and information technology college. The study population confined to the registered and regular students. External students and students who deleted the semester were excluded from this study.

The stratified random sampling was used to select the collages. Stratification was based on the collage being medical or non-medical. At the level of the selected collages, students were chosen by systematic sampling.

The sample size was selected according to the following Formula:

$\mathrm{Z}^{2} \times \mathrm{pq} / \mathrm{d}^{2}$

$\mathrm{Z}=$ Standard normal deviate $=1.96$

$\mathrm{P}=$ prevalence $=0.3^{16}$

$\mathrm{q}=1-\mathrm{p}$

$\mathrm{d}=$ accepted error $=0.05$

Sample size $=1.96 \times 1.96 \times 0.3 * 0.7 / 0.05 \times 0.05=323$ taken as 325 .

The data was collected by a pre-tested questionnaire to assess awareness of breast cancer among undergraduate female students in Majmaah University. The questionnaire contained socio-demographic characteristics (age, gender, and occupation), knowledge and awareness of breast cancer (nature, risk factors and screening test), breast self-examination awareness/practice. In answering the questions, participants have to choose from (Yes/ No/ I do not know). Each correct answer assigned a score of 1, while an incorrect answer or "don't know" scored zero. A total score for each participant was computed by summation of the number of correct answer.

The mean percentage score for awareness was calculated as follows:

(Sum of scores obtained/maximum scores that could be obtained $\times 100$ ). 
Then the studied variables were expressed as falling between $0 \%$ and $100 \%$ with the highest percentage reflecting the increase in that characteristic/variable. For example, a $100 \%$ mean percentage score indicated the highest level of awareness and $0 \%$ indicates no awareness at all. The students who had a total mean score from $0 \%$ to $33.3 \%$ were considered to have poor knowledge, those who acquired a mean score knowledge between $33.4 \%$ $67.6 \%$ and $66.7 \%-100 \%$ were considered to have average and good knowledge respectively. Data was analysed by the computer program using SPSS Version 20. Informed concert was obtained from the participants and the study was approval by the ethics committee of the basic health and medical research centre, Majmaah University. Permission and coordination took place with the administration of the selected collages.

\section{RESULTS}

Figure 1 shows the level of awareness about carcinoma breast of Majmaah University students which shows that
111 (34.2\%) had good knowledge, 137 (42.2\%) had average knowledge while $77(23.6 \%)$ had poor knowledge.

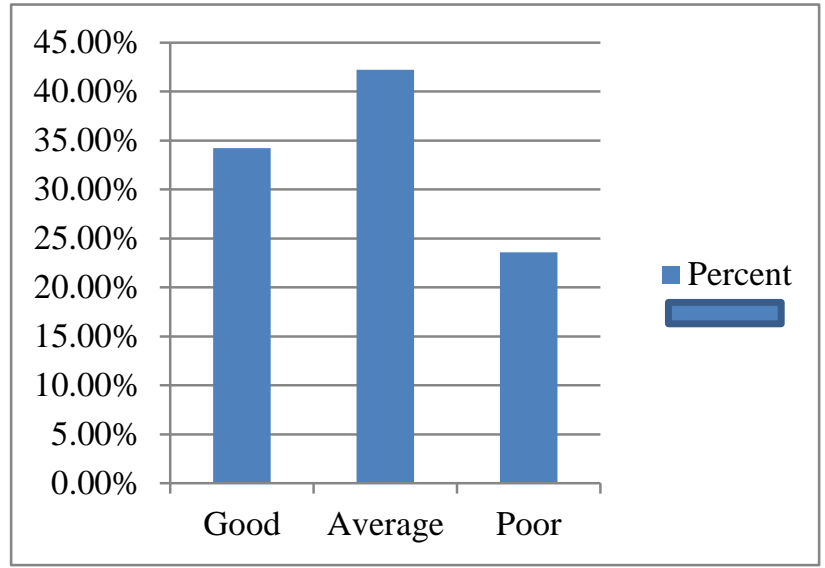

Figure 1: Level of awareness of the students about breast cancer.

Table 1: Level of awareness and type of students.

\begin{tabular}{|c|c|c|c|c|c|}
\hline \multirow{2}{*}{ Type of students } & \multicolumn{3}{|c|}{ Level of awareness } & \multirow{2}{*}{ Total } & \multirow{2}{*}{$\mathbf{P}$} \\
\hline & Good & Average & Poor & & \\
\hline Medical & $86(37.1 \%)$ & $98(42.2 \%)$ & $48(20.7 \%)$ & $232(100 \%)$ & \multirow{3}{*}{0.15} \\
\hline Non- medical & $25(26.9 \%)$ & $39(41.9 \%)$ & $29(31.2 \%)$ & $93(100 \%)$ & \\
\hline Total & $111(34.2 \%)$ & $137(42.2 \%)$ & $77(23.7 \%)$ & $325(100 \%)$ & \\
\hline
\end{tabular}

Table 2: Status of practicing breast self-examination according to student type.

\begin{tabular}{|c|c|c|c|c|}
\hline \multirow[b]{2}{*}{ Type of student } & \multicolumn{2}{|c|}{ Performing breast-self examination } & \multirow[b]{2}{*}{ Total } & \multirow[b]{2}{*}{$\mathbf{p}$} \\
\hline & $\begin{array}{l}\text { Yes } \\
\text { No. }(\%)\end{array}$ & $\begin{array}{l}\text { No } \\
\text { No. }(\%)\end{array}$ & & \\
\hline Medical & $66(28.4 \%)$ & $166(71.6 \%)$ & 232 & \\
\hline Non-medical & $28(30.1 \%)$ & $65(69.9 \%)$ & 93 & \\
\hline Total & $25(28.9 \%)$ & $300(71.1 \%)$ & 325 & 0.79 \\
\hline
\end{tabular}

Table 3: Performing screening test according to students' type.

\begin{tabular}{|c|c|c|c|c|}
\hline \multirow[b]{2}{*}{ Type of student } & \multicolumn{2}{|c|}{ Performing screening test } & \multirow[b]{2}{*}{ Total } & \multirow[b]{2}{*}{$\mathbf{p}$} \\
\hline & $\begin{array}{l}\text { Yes } \\
\text { No. }(\%)\end{array}$ & $\begin{array}{l}\text { No } \\
\text { No. }(\%)\end{array}$ & & \\
\hline Medical & $12(5.2 \%)$ & $220(94.8 \%)$ & 232 & \multirow{3}{*}{0.035} \\
\hline Non-medical & $13(14 \%)$ & $80(86 \%)$ & 93 & \\
\hline Total & $25(7.6 \%)$ & $300(92.4 \%)$ & 325 & \\
\hline
\end{tabular}

Table 1 shows the level of awareness and type of students. Eighty six $(37.06 \%)$ of medical students had good knowledge, 98 (42.24\%) had average knowledge and $48(20.7 \%)$ had poor knowledge. In non-medical students, 25 (26.9\%) had good knowledge, 39 (41.9\%) had average knowledge while $29(31.2 \%)$ had poor knowledge. 
Table 2 shows the status of practicing breast selfexamination. Overall $94(28.9 \%)$ of the participants practice regular BSE. Sixty six $(28.4 \%)$ of the medical students and $28(30.1 \%)$ of the non-medical students practice BSE regularly; the relation between student type and BSE practice is not significant $(\mathrm{p}=0.79)$.

Table 3 shows that the status of performing screening test according to student type, twenty five $(7.6 \%)$ of all the students performed a screening test for breast cancer in the past. Twelve $(5.2 \%)$ of the medical students and 13 (14\%) of the non-medical students performed a screening test for Ca breast.

\section{DISCUSSION}

Breast cancer is a common health problem in Saudi Arabia. Raising awareness will lead to early detection of breast cancer and play an important role in reducing complications and mortality. ${ }^{17}$ Regarding the level of awareness results showed that $34.2 \%$ of the respondents had good knowledge. This level awareness is higher than that reported among students of University of Sharjah and Ajman of UAE and Jordan. ${ }^{18-20}$

This level of knowledge is less than what had been reported by Latif $\mathrm{R}$, among Saudi University females in Al Madina Al Munawara This finding of inadequate breast cancer knowledge is consistent with other studies in Saudi Arabia. ${ }^{11,21}$ The level of Ca breast awareness among medical students was higher than the non-medical students but the relation was not significant $(p=0.15)$. This finding is expected since medical students may have some knowledge of $\mathrm{Ca}$ breast in their curriculum. They also increase their knowledge through elective readings, workshops and conferences.

Regarding breast self-examination (BSE), only $28.9 \%$ of the subjects perform regular BSE. This rate is lower than the students in Kirkuk University, Iraq, where $42.6 \%$ practice BSE. ${ }^{18}$ Compared to studies in Saudi Arabia, this level of practicing regular BSE is less than what has been reported from Al Madina Al Munawara (57.8\%). ${ }^{11}$ However this rate of BSE is higher than the rate of $8.7 \%$ reported in University of Dammam. ${ }^{21}$ Twenty eight $(30.1 \%)$ of the non-medical students perform regular BSE. This rate is higher than the $21 \%$ of women who practice BSE in Kuwait and women from different regions of Saudi Arabia. ${ }^{15,22}$ This rate of BSE is lower than the $49.9 \%$ reported in Hail north Saudi Arabia. ${ }^{35}$ Most female medical students in our sample don't perform BSE; those who perform were $28.4 \%$. This rate is higher than the rate of $17 \%$ of medical students in Taief University. ${ }^{23}$

The finding of low BSE practice especially among medical university students is very alarming for the medical students practice less than the non-medical students, this may be an obstacle to screening and raising awareness programs as long as an early diagnosis of breast cancer in the community.

In this study, only $25(7.6 \%)$ of the participants performed the screening test for Ca breast. This finding is consistent with the results of a survey in different regions of Saudi Arabia. ${ }^{24}$ This result of conducting screening test was less than some findings from Egypt (32.3\%), Qatar $(26.9 \%)$ and eastern province of Saudi Arabia (14.5\%). ${ }^{25-}$ 27 The rate of performing screening test in this analysis is higher than the finding in students of University of Dammam where none of the participants had undergone a screening test for Carcinoma breast. ${ }^{21}$

\section{CONCLUSION}

The study concluded that Majmaah University students' awareness of carcinoma breast is low. There is no significant difference in the level of awareness between students of medical colleges and those of non-medical colleges. The level of practicing breast self-examination among female university students is low; there is no significant difference between the medical and nonmedical students in performing BSE. Few students used to perform screening test for carcinoma breast. Performance of non- medical students in screening for carcinoma breast is significantly higher than in medical students. The study highlighted the importance of establishment of carcinoma breast control program.

\section{ACKNOWLEDGEMENTS}

The authors would like to acknowledge the deans faculty who accepted to cooperate in this study. Our thanks extend to the students who participated in this work.

Funding: No funding sources

Conflict of interest: None declared

Ethical approval: The study was approved by the Institutional Ethics Committee

\section{REFERENCES}

1. Ministry of Health, Saudi Arabia. The Saudi Center for Evidence Based Health Care. Breast Cancer: Clinical Practice Guideline of the use of Screening Strategies for the detection of Breast Cancer, 2014.

2. Varughese $\mathbf{J}$ and Richman S. Cancer Care Inequity for Women in Resource-Poor Countries. Rev Obstet Gynecol. 2010;3(3):122-32.

3. Boyle P, Levin, B. World Cancer Report 2008. International Agency for Research on Cancer; pp. $510 \quad$ pp. ISBN978-92-832-0423-7 Record Number20103010665.http://www.cabdirect.org/ abstracts $/ 20103010665 . \mathrm{html}$;jsessionid=C137ED83 26F02D5184CAB48BB46CE190.

4. Michel P, Coleman MP. Cancer survival in five continents: a worldwide population-based study (CONCORD). The Lancet Oncology. 2008;9(18639491):730-75. 
5. Agarwal G, Pradeep PV, Aggarwal V, Yip CH, Cheung PS. Spectrum of breast cancer in Asian women. World J Surg. 2007;31(5):1031-40.

6. World Health Organization. Global Status Report on Non-communicable Diseases 2010. From: www.who.int/nmh/publications/ncd_report_full_en. pdf?ua=1 Accessed on Dec, 2015.

7. Alharbi NA, Alshammari MS, Almutairi BM, Makboul G, El-Shazly MK. Knowledge, awareness and practices concerning breast cancer among Kuwaiti female school teachers, Alexandria Journal of Medicine. 2012;48:75-82.

8. Bener A, Alwash R, Miller CJ, Denic S, Dunn E. Knowledge, attitudes, and practices related to breast cancer screening: a survey of Arabic women. J Cancer Educ. 2001;16(4):215-20.

9. Female breast cancer. Riyadh: Saudi Cancer Registry 2009 -2011 From: http://www.scr.org.sa/ ?module $=$ publications \& page $=$ list $\&$ id $=46 \&$ page_num= Accessed on 1.12.2015.

10. Al Mulhim FA, Syed A, Bagatadah WA, Al Muhanna FA. Breast cancer screening program: experience from Eastern province, Saudi Arabia. EMHJ. 2015;21(2):111-9.

11. Habib F, Salman S, Safwat M, Shalaby S. Awareness and knowledge of breast cancer among university students in $\mathrm{Al}$ Madina $\mathrm{Al}$ Munawara Region. Middle East Journal of Cancer. 2010;1(4).

12. Al-Eid HS, Garcia AD. Saudi Cancer Registry: Cancer Incidence report 2009. Ministry of Health, Saudi Arabia; 2012.

13. Radi SM. Breast cancer awareness among Saudi Females in Jeddah. Asian Pac J Cancer Prev. 2013;14(7):4307-12.

14. Hussein DM. Breast cancer awareness and breast self-examination in Northern Saudi Arabia. Saudi Med Journal. 2013;34:681-8.

15. Ahmed AS, El-Gharabawy RM, AL-Suhaibany OH. Knowledge, attitude and practice about breast cancer among women in Saudi Arabia. International Archives of Medicine. 2015;8(248).

16. Al-AzmyM SF, Alkhabbaz A, Almutawa HA, Ismaiel AE, Makboul G, El-Shazly MK. Practicing breast self-examination among women attending primary health care in Kuwait. Alexandria Journal of Medicine. 2013;49:281-6.

17. Yousuf SA. Breast cancer awareness among Saudi nursing students. JKAU: Med Sci. 2010;17(3):6778.
18. Alwan NAS, Al-Diwan JKA, Al-Attar WM, Eliessa RA. Knowledge, attitude \& practice towards breast cancer \& breast self- examination in Kirkuk University, Iraq. Asian Pacific Journal of Reproduction. 2012;1(4):308-11.

19. Suleiman AK. Awareness and attitudes regarding breast cancer and breast self-examination among female Jordanian students. J Basic Clin Pharm. 2014;5(3):74-8.

20. Al-Sharbatti SS, Shaikh RB, Mathew E, Al-Biate MA. Assessment of Breast Cancer Awareness among Female University Students in Ajman in United Arab Emirates. Sultan Qaboos University Med J, November 2014;14 (4): e522-529.

21. Latif R. Knowledge and attitude of Saudi female students towards breast cancer: A cross-sectional study. Journal of Taibah University Medical Sciences. 2014;9(4):328-34.

22. Abduelkarem AR, Saif FK, Saif S, Alshoaiby TA. Evaluation of breast cancer awareness among female university students in university of Sharjah, UAE. Advances in Breast Cancer Research. 2015;4:9-21.

23. Nemenqani DM, Abdelmaqsoud SH, Al-Malki AA. Knowledge, attitude and practice of breast selfexamination and breast cancer among female medical students in Taif, Saudi Arabia. Open Journal of Preventive Medicine. 2014;4(2):69-77.

24. El Bcheraoui C, Basulaiman M, Wilson S, Daoud F, Tuffaha M, AlMazrroaMA. Breast Cancer Screening in Saudi Arabia: Free but Almost No Takers. PLOS ONE. 2015;10(3).

25. Elshamy KF, Shoma AM. Knowledge and Practice of Breast Cancer Screening Among Egyptian Nurses. African Journal of Haematology and Oncology. 2010;1(4).

26. Donnelly TT, Al Khater A, Al-Bader SB, Al Kuwari MG, Malik M, Al-Meer N. Factors that influence awareness of breast cancer screening among Arab women in Qatar: results from a cross sectional survey. Asian Pacific Journal of Cancer Prevention. 2014;15(23).

27. Al-Mulhim FA. Knowledge and attitude towards screening mammography among 400 women in the eastern province of Saudi Arabia. J Family Community Med. 2001;8(3):73-8.

Cite this article as: Mohamed EY, Sami W, Alenezi AA, Almutairi AM, Alsalboud AK, Alhusainy KM, et al. Breast cancer awareness and breast selfexamination among future female university graduates: comparison between medical and nonmedical students. Int J Res Med Sci 2016;4:685-9. 